(C)2010 IEEE. Personal use of this material is permitted. However, permission to reprint/republish this material for advertising or promotional purposes or for creating new collective works for resale or redistribution to servers or lists, or to reuse any copyrighted component of this work in other works must be obtained from the IEEE. 


\title{
Economic Transmission Augmentation With Explicit Modeling of the Competition Benefit
}

\author{
Mohammad R. Hesamzadeh, Graduate Student Member, IEEE, Darryl R. Biggar, \\ Nasser Hosseinzadeh, Member, IEEE, and Peter J. Wolfs, Senior Member, IEEE
}

\begin{abstract}
This paper derives and evaluates a mathematical structure for identifying economically-efficient transmission augmentations. The mathematical structure is based on the concepts of sequential-move and simultaneous-move games in applied mathematics. The Nash equilibrium solution concept has been reformulated as an optimization problem in the proposed structure. The problem of multiple Nash equilibria is managed by introducing the concept of the worst-case Nash equilibrium. Both the economic concepts of the "efficiency benefit" and "competition benefit" of the transmission capacity are explicitly modeled in the proposed structure. A simple three-bus example system and Garver's example system are employed and modified to suit the purpose of analysis. A thorough economic study of these example systems is presented to highlight the concept and operation of the proposed mathematical structure from different perspectives. The results demonstrate the utility of the proposed structure for measuring the total economic efficiency benefit of additional transmission capacity.
\end{abstract}

Index Terms-Competition benefit, economic transmission augmentation, efficiency benefit, Nash equilibrium.

\section{INTRODUCTION}

$\mathbf{E}$ CONOMIC augmentation of a transmission system is defined as those augmentations that are not required for the enhancement of system reliability, [1], [2].

Optimal expansion of the transmission network is a critical element of overall efficient operation of and investment in a liberalized electricity market. Insufficient transmission capacity results in five main costs: Higher than optimal congestion, higher than optimal power losses, lower than optimal reliability, imperfect competition in generation, and inefficient outcomes in the electricity market [3]. But how should we go about assessing the economic benefit from a transmission augmentation? References [3] and [4] set up a framework for transmission planning based on the marginal economic value of transmission capacity. Reference [5] employs the same mathematical structure as [3], but uses congestion cost and congestion revenue as the driving signals of the need for network expansion. This framework has two main shortcomings: the lack of determination of the efficient level of congestion for a transmission network and the lack of separate determination of the "competition benefit" of transmission capacity. References [6] and [7] suggest a new

Manuscript received April 13, 2009; revised December 08, 2009. Paper no. TPWRS-00236-2009.

M. R. Hesamzadeh and N. Hosseinzadeh are with Swinburne University of Technology, Melbourne, Vic 3122, Australia.

D. R. Biggar is with the Australian Competition and Consumer Commission (ACCC), Melbourne, Australia.

P. J. Wolfs is with Curtin University of Technology, Perth, Australia.

Digital Object Identifier 10.1109/TPWRS.2009.2039233 algorithm for transmission augmentation based on the congestion cost and the notion of "flatness" of the nodal price profile. However, the variability of electricity prices over a transmission network is not an exact measure of competitiveness and is not suitable for identifying system bottlenecks [5]. In addition, the planning process does not have a closed-form mathematical formulation. Furthermore, this approach is unsuccessful in modeling the interaction between the availability of transmission capacity and market power in generation. Reference [8] suggests two heuristic procedures for assessing transmission augmentation. The authors use an unconstrained oligopoly equilibrium for the set of producers' bids, while bids from the demand side are assumed to be fixed and derived from analysis of the existing market data. However, an unconstrained oligopoly equilibrium cannot capture the impact of transmission congestion.

On the other hand, [9] showed numerically that transmission expansion reduces generators' market power. Reference [10] empirically examined the bidding behavior of generators in England and Wales, including the impact of transmission constraints. The authors report that in England and Wales generators protected by transmission constraints bid significantly higher than those not protected. References [11] and [12] show that generators benefit from a reduction in transmission capacity. Using a simplified version of the power network in California, [13] has quantified the impact of local market power and transmission capacity. Using a stylized version of the North American transmission system, [14] highlights the effect of transmission capacity on competition among generating companies (GenCos). Unlike the efficiency effect of transmission capacity, the competition effect has not received enough attention in transmission planning methodologies. In the survey articles [15]-[17] no mention is made of literature on the modeling of market power and the assessment of competition benefits as a component of economic transmission augmentation.

The TEAM methodology introduced by the California ISO [18] is one possible model for analyzing economic-efficiencybased transmission augmentation. However, it has two drawbacks. First, the strategic bidding of GenCos was modeled using a tailor-made methodology which limits its application. Second, the approach does not have an integrated mathematical framework.

In the Australian National Electricity Market (NEM) the "regulatory test" introduced by the Australian Competition and Consumer Competition (ACCC) is used as the transmission augmentation criterion by the transmission network service providers in different states. In February 2003, the ACCC published a discussion paper reviewing the regulatory test. In that report, whether or not the "competition benefit" of transmission capacity should be included in the regulatory test was one of the key themes discussed. Traditionally, in Australia modeling 
of the operation of the transmission system for the purposes of assessing a proposed augmentation has assumed a simplified form of generator behavior (such as assuming generators bid at marginal cost). This approach has ruled out calculation of the impact of a transmission augmentation on competition between generators. Reference [19] reviews the practical implementation issues arising from the different approaches to the measurement of competition benefits proposed by interested parties. Reference [20] proposes a heuristic approach for evaluating competition benefits of transmission capacity. But the question of how best to compute the competition benefit of a transmission augmentation in the context of the regulatory test is still largely unresolved.

Using multilevel programming, this paper derives a closedform mathematical structure for assessing a transmission augmentation. The Nash equilibrium solution concept is employed to model the future condition of the electricity market. The various Nash equilibria are formulated as the zeros of a nonnegative function. The "worst-case" Nash equilibrium is selected as the relevant equilibrium point of the electricity market for the purposes of transmission planning.

The proposed approach is illustrated using a simple three-bus example system and a modified Garver's example system.

The mathematical derivation of the problem is set out in Section II. The experimental results and discussions are set out in Section III. Section IV concludes.

\section{MATHEMATICAL DeRIVATION OF THE PROPOSED STRUCTURE}

In the light of the electricity market in Australia, the owner and operator of the transmission network-the transmission network service provider (TNSP) - is assumed to be a regulated monopoly business. The TNSP is required, amongst other things, to efficiently plan the transmission network and provide a competitive environment for market participants. The GenCos are assumed to be independent commercial entities whose objective is to maximize their economic profit (revenues less costs). Finally, the market management company (MMC) is assumed to play the role of manager and operator of the electricity market. The MMC is completely independent from both the TNSPs and the GenCos. We consider a decentralized noncooperative decision system with one leader and several followers. We assume that the leader and followers may have their own decision variables and objective functions. The leader can only influence the reaction of followers through his own decision variables, while the followers have full authority to decide how to optimize their objective functions with respect to the leader's decision as well as other followers' decisions. Multilevel programming [21] is used to find the optimal transmission augmentation path.

Section II-A deals with the application of the Nash concept for modeling competition between GenCos. The formulation of the Nash equilibrium concept as an optimization problem enables the structure to identify all the Nash equilibria of the game. Section II-B models the TNSP as the leader of the two-stage game. The problem of multiple Nash points is tackled through the selection of the socially "worst" Nash equilibrium in terms of total cost of generation and total value of lost load.

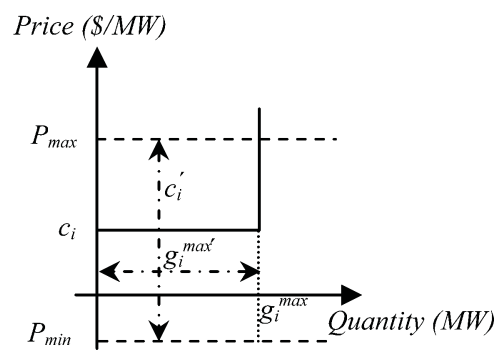

Fig. 1. Marginal cost curve and the biding strategy of a GenCo.

\section{A. Nash Equilibria of the Simultaneous Move Price-Quantity Game Among GenCos as Zeros of R Function}

The cost function of a generating company can be modeled as a quadratic function of the form (1):

$$
\mathrm{C}\left(\mathrm{g}_{\mathrm{i}}\right)=\mathrm{b}_{\mathrm{i}}+\mathrm{c}_{\mathrm{i}} \mathrm{g}_{\mathrm{i}}+\mathrm{a}_{\mathrm{i}} \mathrm{g}_{\mathrm{i}}^{2} \quad 0 \leq \mathrm{g}_{\mathrm{i}} \leq \mathrm{g}_{\mathrm{i}}^{\max } .
$$

In (1), $\mathrm{a}_{\mathrm{i}}\left(\$ / \mathrm{MW}^{2}\right), \mathrm{b}_{\mathrm{i}}(\$)$, and $\mathrm{c}_{\mathrm{i}}(\$ / \mathrm{MW})$ are the cost function coefficients. The quadratic cost function can be approximated by a linear function of the form (2):

$$
\mathrm{C}\left(\mathrm{g}_{\mathrm{i}}\right)=\mathrm{b}_{\mathrm{i}}+\mathrm{c}_{\mathrm{i}} \mathrm{g}_{\mathrm{i}} \quad 0 \leq \mathrm{g}_{\mathrm{i}} \leq \mathrm{g}_{\mathrm{i}}^{\max } .
$$

In (2), $\mathrm{g}_{\mathrm{i}}^{\max }$ is the total generation capacity, and $\mathrm{g}_{\mathrm{i}}$ is the generation level of GenCo $i$ assigned by the MMC. Each GenCo offers a price-quantity pair $\left(c_{i}^{\prime}, g_{i}^{m^{\prime} x^{\prime}}\right)$ to the MMC to participate in the market. The marginal cost of a GenCo and its bidding strategy are shown in Fig. 1.

$\mathrm{P}_{\min }(\$)$ and $\mathrm{P}_{\max }(\$)$ are the minimum and maximum limits on a price offer of a GenCo. These limits are usually set by the electricity market regulator. Competition on price (the so-called "Bertrand" game), competition on quantity (the so-called "Cournot" game), and competition on both price and quantity are permitted in this structure. Given the bidding strategies of other GenCos and the current state of the network, each GenCo finds its optimal strategy using the bilevel programming problem set out in (3):

$$
\begin{aligned}
& \operatorname{Max}_{c_{i}^{\prime}, g_{i}^{\max ^{\prime}}}\left[v_{i} g_{i}-C\left(g_{i}\right)\right] \\
& \text { s.t. } \\
& P_{\min } \leq c_{i}^{\prime} \leq P_{\max } \\
& 0 \leq g_{i}^{\max ^{\prime}} \leq g_{i}^{\max } \\
& \operatorname{Min}_{g, d, \theta, f_{i j}}\left[\sum_{i \in G} c_{i}^{\prime} g_{i}+\sum_{i \in D} \operatorname{VoLL}_{i}\left(d_{i}^{\max }-d_{i}\right)\right] \\
& \text { s.t. } \\
& \quad[B] \theta=g-d \leftrightarrow v \\
& \quad f_{i j}-\gamma_{i j}\left(n_{i j}^{0}+n_{i j}\right)\left(\theta_{i}-\theta_{j}\right)=0 \quad \forall(i, j) \in L \\
& \quad\left|f_{i j}\right| \leq\left(n_{i j}^{0}+n_{i j}\right) f_{i j}^{\max } \quad \forall(i, j) \in L \leftrightarrow u_{1} \\
& \quad 0 \leq g \leq g^{\max } \quad \leftrightarrow u_{2} \\
& \quad 0 \leq d \leq d^{\max } \leftrightarrow u_{3} .
\end{aligned}
$$

In (3), VoLL is the value of lost load, [B] is a $\mathrm{N}_{\mathrm{b}} \times \mathrm{N}_{\mathrm{b}}$ matrix with $\mathrm{N}_{\mathrm{b}}$ as the total number of buses in the system. $\theta$ is the vector of bus angles, $g$ and $d$ are the generation level of committed generators and the served demand of retailers. $f_{i j}$ is the MW flow between nodes $i$ and $j, f_{i j}$ max is the maximum thermal capacity for the branch ij. Also, $\gamma_{i j}$ is the susceptance of the 
branch ij in mho, $\mathrm{n}_{i j}^{0}$ is the existing number of circuits, and $\mathrm{n}_{i j}$ is the TNSP decision variable on new circuits. Vectors $u$ and $v$ are the Lagrange multipliers of the associated constraints. The vector $\mathrm{v}$ is the price of energy at different network connection points.

Using the Karush-Kuhn-Tucker optimality conditions, (3) can be generalized as in (4):

$$
\operatorname{Max}_{\substack{y_{i} \in Y_{i} \\ z \in Z}} f_{i}\left(x, y_{i}, y_{-i}, z\right)
$$

where in (4), $\mathrm{x}=\mathrm{n}$ is the TNSP decision vector, $y_{i}=\left(c_{i}^{\prime}, g_{i}^{\max ^{\prime}}\right)$ is the action vector of the $i$ th GenCo, and $\mathrm{y}$ is the vector $\left(\mathrm{y}_{1}, \ldots, \mathrm{y}_{\mathrm{i}-1}, \mathrm{y}_{\mathbf{i}+1}, \ldots, \mathrm{y}_{\mathrm{m}}\right)$ with $m$ as the total number of GenCos. The vector $\mathrm{z}$ is equal to $(\mathrm{g}, \mathrm{d}, \theta, \mathrm{u}, \mathrm{v})$; this vector is constrained by the set $\mathrm{Z}$, which is the set defined by the constraints of the inner optimization problem in (3).

Since all GenCos are of equal status, they must reveal their strategies simultaneously. The most common solution concept in this context is the Nash equilibrium.

The Nash equilibrium problem can be formulated as the problem of finding the zeros of a function $\mathrm{R}$ which is defined in (5).

Definition 1: Let $\mathrm{Y}$ be a nonempty set which defines the strategy space of all GenCos participating in the electricity market. The function $\mathrm{R}(\mathrm{y}): \mathrm{Y} \rightarrow \mathbf{R}^{+}$is defined as (5):

$$
R(y)=\sum_{i=1}^{m}\left[\operatorname{Max}_{\substack{y_{i} \in Y_{i} \\ z \in Z}} f_{i}\left(x, y_{i}, y_{-i}, z\right)-f_{i}(x, y, z)\right] \text {. }
$$

The following theorem follows:

Theorem: The function $\mathrm{R}(\mathrm{y}): \mathrm{Y} \rightarrow \mathbf{R}^{+}$is real and nonnegative on Y. Also, Nash equilibria are the zeros of $\mathrm{R}$.

Proof: Let $y_{i}$ be a strategy that belongs to a strategy space $\mathrm{Y}_{\mathrm{i}}$ and $\pi_{\mathrm{i}}$ be the profit function of player $i$ in game G. Also, let $y_{-i}$ be the strategy of all other players of the game $\mathrm{G}$ except player $i . y^{*}=\left(y_{1}^{*}, y_{2}^{*}, \ldots, y_{i}^{*}, \ldots y_{n}^{*}\right)$ is the Nash equilibrium of the game $\mathrm{G}$ if for every player $i$ and for every strategy $y_{i}$,

$$
\begin{aligned}
\pi_{i}\left(y_{i}^{*}, y_{-i}^{*}\right) & \geq \pi_{i}\left(y_{i}, y_{-i}^{*}\right) \rightarrow R_{i}\left(y_{i}, y_{-i}^{*}\right) \\
& =\pi_{i}\left(y_{i}^{*}, y_{-i}^{*}\right)-\pi_{i}\left(y_{i}, y_{-i}^{*}\right) \geq 0 .
\end{aligned}
$$

If we define $R(y)=\sum R_{i}$, then

$$
R(y)=0 \leftrightarrow y=y^{*}
$$

The mathematical framework for competition among GenCos can be now set out as in (6):

$$
\begin{aligned}
& \operatorname{Min}_{c_{i}^{\prime}, g_{i}^{\max ^{\prime}}} \sum_{i=1}^{m}\left[\operatorname{Max}_{\substack{y_{i} \in Y_{i} \\
z \in Z}} f_{i}\left(x, y_{i}, y_{-i}, z\right)\right. \\
& \left.-\left[v_{i} g_{i}-C\left(g_{i}\right)\right]\right] \\
& \text { s.t. } \\
& P_{\min } \leq c_{i}^{\prime} \leq P_{\max } \\
& 0 \leq g_{i}^{\max ^{\prime}} \leq g_{i}^{\max } \\
& \operatorname{Min}_{g, d, \theta, f_{i j}}\left[\sum_{i \in G} c_{i}^{\prime} g_{i}+\sum_{i \in D} \operatorname{VoLL}_{i}\left(d_{i}^{\max }-d_{i}\right)\right] \\
& \text { s.t. } \\
& \quad[B] \theta=g-d \leftrightarrow v \\
& \quad f_{i j}-\gamma_{i j}\left(n_{i j}^{0}+n_{i j}\right)\left(\theta_{i}-\theta_{j}\right)=0 \quad \forall(i, j) \in L \\
& \left|f_{i j}\right| \leq\left(n_{i j}^{0}+n_{i j}\right) f_{i j}^{\max } \quad \forall(i, j) \in L \leftrightarrow u_{1}
\end{aligned}
$$

$$
\begin{aligned}
& 0 \leq g \leq g^{\max ^{\prime}} \leftrightarrow u_{2} \\
& 0 \leq d \leq d^{\max } \leftrightarrow u_{3}
\end{aligned}
$$

If an array $\mathrm{y}=\left(\mathrm{y}_{1}, \ldots, \mathrm{y}_{\mathrm{i}}, \ldots, \mathrm{y}_{\mathrm{m}}\right)$ satisfies $\mathrm{R}\left(\mathrm{y}_{1}, \ldots, \mathrm{y}_{\mathrm{i}}, \ldots, \mathrm{y}_{\mathrm{m}}\right)=0$, then $\mathrm{y}$ must be a solution of (6) and consequently a Nash equilibrium of the game. The set of all optimal solutions of (5) are the Nash equilibria of the price-quantity game among GenCos. If (5) does not have any optimal solution, there is no Nash equilibrium of GenCos in the given programming problem. Section II-B addresses the issue of multiple Nash equilibria and the TNSP objective function.

\section{B. Worst Nash Equilibrium and the TNSP Mathematical Structure for Augmentation}

The set of Nash equilibria of the price-quantity game can be found by solving the optimization problem formulated in (6).

Reference [20] uses averaging to deal with the many Nash equilibria of the quantity game among GenCos. This methodology first calculates the market outcome under each Nash equilibrium and then takes an average for each of the variables of interest for the purposes of transmission augmentation. The problem with this method is that there is no theoretical basis for adopting the average of a set of Nash equilibria. Even more concerning, in many cases the average of the variables of interest may not satisfy simple intuitive relationships (for example, average price differences may arise between locations even when average flows are not at their maximum). This diminishes the value of the results for transmission augmentation decisions.

This paper introduces the concept of the socially worst Nash equilibrium. The worst Nash equilibrium is the one which has the highest social cost to the society. The social cost is defined as the total cost of generation and total value of lost load. The mathematical formulation of the worst Nash equilibrium is set out in (7):

$$
\operatorname{Max}_{c_{i}^{\prime}, g_{i}^{\max ^{\prime}}}\left[\sum_{i \in G} c_{i} g_{i}+\sum_{i \in D} \operatorname{VoLL}_{i}\left(d_{i}^{\max }-d_{i}\right)\right] .
$$

In (7), the objective function is the total cost to society which must be computed for each of Nash equilibria of the GenCos' price-quantity game.

Suppose L is the set of all upgrade and expansion projects available for the TNSP. The $c_{i j}$ is the cost of transmission project between buses $\mathrm{i}$ and $\mathrm{j}$ and $\mathrm{n}_{i j}$ is the number of circuits in the transmission corridor $i-j . \mathrm{n}_{i j}^{\max }$ is the maximum value for the integer variable $\mathrm{n}_{i j}$. The vector $\mathrm{n}$ is the TNSP's design parameter.

The mathematical structure of the TNSP's problem can be formulated as (8):

$$
\begin{aligned}
& \operatorname{Min}_{n_{i j}} \pi=\sum_{(i, j) \in L} c_{i j} n_{i j} \\
& \quad+\sigma \operatorname{Max}_{c_{i}^{\prime}, g_{i}^{\max ^{\prime}}} \\
& \quad \times\left[\sum_{i \in G} c_{i} g_{i}+\sum_{i \in D} \operatorname{VoLL}_{i}\left(d_{i}^{\max }-d_{i}\right)\right] \\
& \text { s.t. } \\
& 0 \leq n_{i j} \leq n_{i j}^{\max } \forall(i, j) \in L, n_{i j} \in N \\
& \operatorname{Min}_{c_{i}^{\prime}, g_{i}^{\max ^{\prime}}} \sum_{i=1}^{m}\left[\operatorname{Max}_{\substack{y_{i} \in Y_{i} \\
z \in Z}} f_{i}\left(x, y_{i}, y_{-i}, z\right)\right.
\end{aligned}
$$




$$
\begin{aligned}
& \left.-\left[v_{i} g_{i}-C\left(g_{i}\right)\right]\right] \\
& \text { s.t. } \\
& \begin{array}{l}
P_{\min } \leq c_{i}^{\prime} \leq P_{\max } \\
0 \leq g_{i}^{\max ^{\prime}} \leq g_{i}^{\max } \\
\operatorname{Min}_{g, d, \theta, f_{i j}}\left[\sum_{i \in G} c_{i}^{\prime} g_{i}\right. \\
\left.\quad+\sum_{i \in D} \operatorname{VoLL}_{i}\left(d_{i}^{\max }-d_{i}\right)\right] \\
\quad s . t . \\
\quad[B] \theta=g-d \leftrightarrow v \\
f_{i j}-\gamma_{i j}\left(n_{i j}^{0}+n_{i j}\right)\left(\theta_{i}-\theta_{j}\right)=0 \forall(i, j) \in L \\
\left|f_{i j}\right| \leq\left(n_{i j}^{0}+n_{i j}\right) f_{i j}^{\max } \quad \forall(i, j) \in L \leftrightarrow u_{1} \\
0 \leq g \leq g^{\max } \leftrightarrow u_{2} \\
0 \leq d \leq d^{\max } \leftrightarrow u_{3} .
\end{array}
\end{aligned}
$$

The objective function in (8) is the sum of the transmission investment cost of upgrade/expansion projects, the operating cost of the GenCos, and the total value of lost load when GenCos exercise market power. The difference between the overall social cost when the GenCos exercise market power when all the GenCos are price-takers (i.e., have no market power) is the competition benefit of the additional transmission capacity. Note that the "competition benefit" is the additional market benefit brought about by enhanced generator competition resulting from the transmission augmentation. The transmission planning schedule is for the highest forecast demand in the horizon year of planning. The coefficient $\sigma$ is the duration of this load scenario in hours.

The overall social objective is to upgrade and/or expand the transmission system with the minimum overall social cost.

The optimization problem set out in (8) is a closed-form mathematical structure for the assessment of transmission augmentation. In (8), the TNSP moves first and designs the future transmission system. Based on the planning schedule, the Nash equilibria of the price-quantity game are calculated. In the next step, the worst Nash equilibrium is found and the generation costs and total value of lost load of the worst Nash equilibrium are added to the TNSP's planning schedule cost to determine the total cost of a particular expansion. The socially-optimal planning schedule is the one which minimizes overall social cost.

\section{EXPERIMENTAL RESULTS AND DISCUSSIONS}

Two example systems, namely, a simple three-node example system and the modified Garver's example system, are used to illustrate the proposed methodology for assessing transmission augmentation.

\section{A. Simple Three-Node Example System}

The proposed approach in (8) is applied first to a simple threenode system, as illustrated in Fig. 2.

Transmission lines $L 1, L 2$, and $L 3$ connect buses 1,2 , and 3 . The transmission investment cost on these lines are 1, 2, and 3 $\mathrm{M} \$ / \mathrm{Cct}$. There are two competing generators labelled GenCo1 and GenCo2, and two competing retailers labelled R1 and R2 in the three-bus example system. The characteristics of the generators, retailers, and the transmission network are set out in

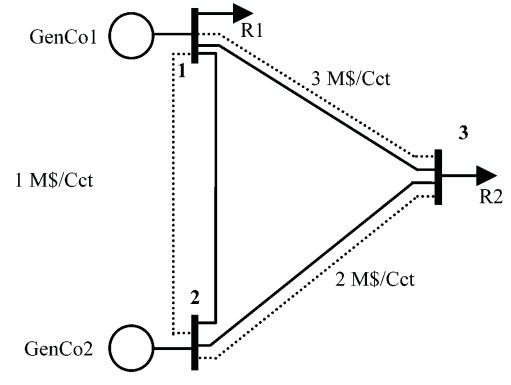

Fig. 2. Single line diagram of the three-node example system.

TABLE I

GENERATORS' DATA

\begin{tabular}{c|c|c}
\hline Generator & $\mathrm{g}^{\max }(\mathrm{MW})$ & $\mathrm{c}=(\$ / \mathrm{MW})$ \\
\hline GenCo1 & 200 & 30 \\
\hline GenCo2 & 200 & 20 \\
\hline
\end{tabular}

TABLE II

RETAILERS' DATA

\begin{tabular}{c|c|c}
\hline Retailer & $\mathrm{d}^{\max }(\mathrm{MW})$ & VoLL $(\$ / \mathrm{MW})$ \\
\hline R1 & 150 & 10,000 \\
\hline R2 & 200 & 10,000 \\
\hline
\end{tabular}

TABLE III

TRANSMISSION NETWORK DATA

\begin{tabular}{c|c|c|c|c}
\hline Line\# & From & To & Reactance(Ohm) & Limit(MW) \\
\hline 1 & B2 & B1 & 0.002 & 70 \\
\hline 2 & B2 & B3 & 0.002 & 140 \\
\hline 3 & B1 & B3 & 0.002 & 70 \\
\hline
\end{tabular}

TABLE IV

TRANSMISSION NETWORK AUgMENTATION DATA

\begin{tabular}{c|c|c|c|c|c|c}
\hline $\begin{array}{c}\text { Line } \\
\#\end{array}$ & From & To & $\begin{array}{c}\text { Max. } \\
\text { number } \\
\text { of } \\
\text { Circuits } \\
\text { (Cct) }\end{array}$ & $\begin{array}{c}\text { Reactance } \\
(\text { Ohm/Cct.) }\end{array}$ & $\begin{array}{c}\text { Capacity } \\
\text { of } \\
\text { each } \\
\text { circuit } \\
\text { (MW) }\end{array}$ & $\begin{array}{c}\text { Transmission } \\
\text { Investment } \\
\text { cost } \\
(\$ / C c t .)\end{array}$ \\
\hline 1 & B2 & B1 & 3 & 0.002 & 20 & $1,000,000$ \\
\hline 2 & B2 & B3 & 3 & 0.002 & 20 & $2,000,000$ \\
\hline 3 & B1 & B3 & 3 & 0.002 & 20 & $3,000,000$ \\
\hline
\end{tabular}

Tables I-III, respectively. The upgrade or expansion projects for the existing transmission system are set out in Table IV.

For each GenCo, the price-quantity pair $\left(c_{i}^{\prime}, g_{i}^{\max ^{\prime}}\right)$ offered to the MMC has been approximated by a set of discrete variables. For demonstrative purposes, the scaling factor on the marginal cost is fixed at 1.0 (so each GenCo bids its "true" marginal cost) and the scaling factor on generation capacity is between $10 \%$ and $100 \%$ of true generation capacity in steps of $1.84 \%$. This is equivalent to 50 different possible announced generation capacities for each GenCo.

Case A: The Traditional Model for Economic-Based Transmission Augmentation: The traditional model of transmission augmentation is a nonconvex, nonlinear, and mixed-integer programming problem. Using the DICOP solver in the GAMS platform [24], the traditional approach to assessing transmission augmentation has been carried out for the three-node example system. The traditional model does not approve any augmentation for the three-node example system set out above. The 


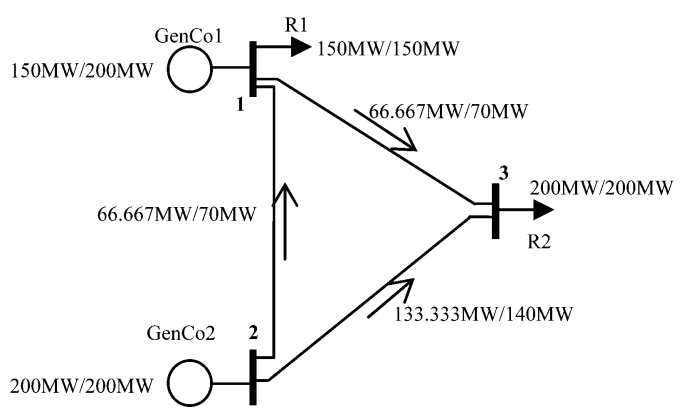

Fig. 3. Economic dispatch results of the three-node example system augmented based on the traditional model; all GenCos are competitive.

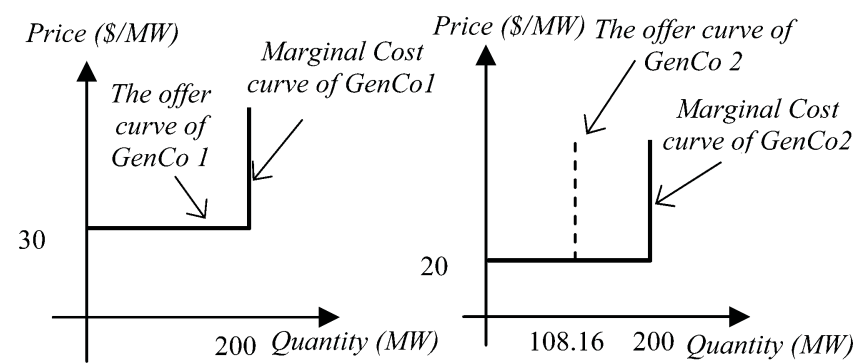

Fig. 4. Marginal cost curve and the strategy curve of GenCo1 and GenCo2 considering the transmission system augmented based on the traditional model.

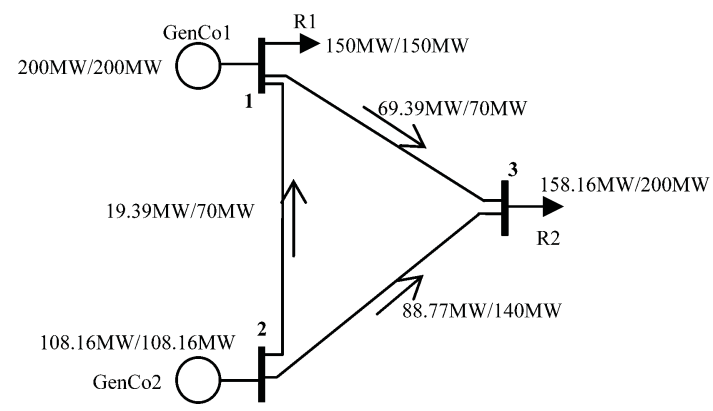

Fig. 5. Economic dispatch results of the three-node example system augmented based on the traditional model; GenCos behave strategically.

dispatch of GenCos, retailers, and the resulting line flows are shown in Fig. 3. Considering the transmission augmentation solution based on the traditional model, the worst Nash equilibrium was found and is as set out in Fig. 4.

As shown in Fig. 4, under the traditional augmentation model, GenCo1 offers its true marginal cost to the MMC, but GenCo2 offers only $108.16 \mathrm{MW}$ of its capacity to the MMC. In other words, GenCo 2 withholds about $50 \%$ of its true capacity.

The dispatch results allowing for the strategic behaviour of GenCos and the augmented transmission system based on the traditional model is shown in Fig. 5.

Under the traditional model of augmentation, the total transmission investment cost is $\$ 0.0$ (since no augmentation is found to be economically justified) and the social cost, based on the worst Nash equilibrium and the weighting factor of $\sigma=10.0$, is $\$ 4294592$.

Case B: The Proposed Model for Economic-Based Transmission Augmentation: The outcome under the traditional approach can now be compared with the outcome under the proposed methodology set out in (8), which approves the building of a 20-MW circuit between nodes 2 and 3 . The worst Nash

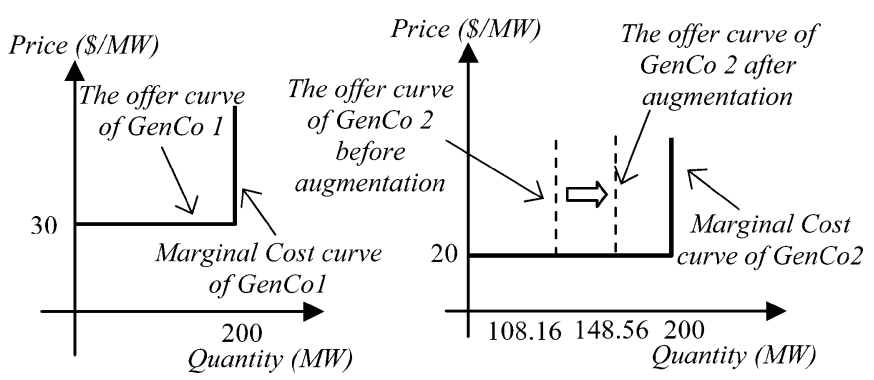

Fig. 6. Marginal cost curve and the strategy curve of GenCo 1 and GenCo2 considering the transmission system augmented based on the proposed model.

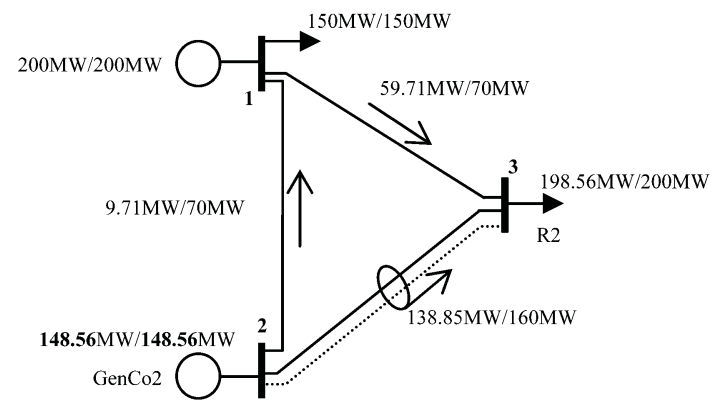

Fig. 7. Economic dispatch results of the three-node example system augmented based on the proposed model; GenCos behave strategically.

equilibrium of GenCo1 and GenCo2 considering the 20-MW augmentation of transmission system is found and is as indicated in Fig. 6.

As is clear from Fig. 6, the additional 20-MW augmentation encourages GenCo 2 to behave more competitively.

In this case, GenCo2 offers $148.56 \mathrm{MW}$ of its capacity to the energy market (compared to 108.16 MW under the traditional approach). The transmission investment cost is $\$ 2 \mathrm{M}$ and the social cost associated with the worst Nash equilibrium of the market with the weighting factor of $\sigma=10.0$ is $\$ 233570$. Under the traditional model, GenCo2 withholds around $50 \%$ of its true capacity from the market. Adding a 20-MW circuit between nodes 1 and 3 causes GenCo2 to offer $148.56 \mathrm{MW}$ of its capacity to the market-an improvement of $50 \%$ over its offered capacity before augmentation. The dispatch results when the GenCos bid strategically and the transmission system has been augmented based on the proposed model is shown in Fig. 7.

The decomposition of the total benefit of the additional transmission capacity into its components, namely, competition benefit and efficiency benefit, using the methodology of part B of the Appendix is illustrated in Fig. 8.

In fact, as shown in Fig. 8, the additional transmission capacity between buses 2 and 3 only has value for improving competition between generators and does not have any traditional efficiency benefit.

\section{B. Modified Garver's Six-Bus Example System}

Let's now apply the proposed methodology to a modified Garver's six-bus example system. Garver's example system has been modified to reflect a network with six buses and eight transmission lines. The key parameters of the system are presented in Tables V-VIII.

The single line diagram of the example system is shown in Fig. 9. 


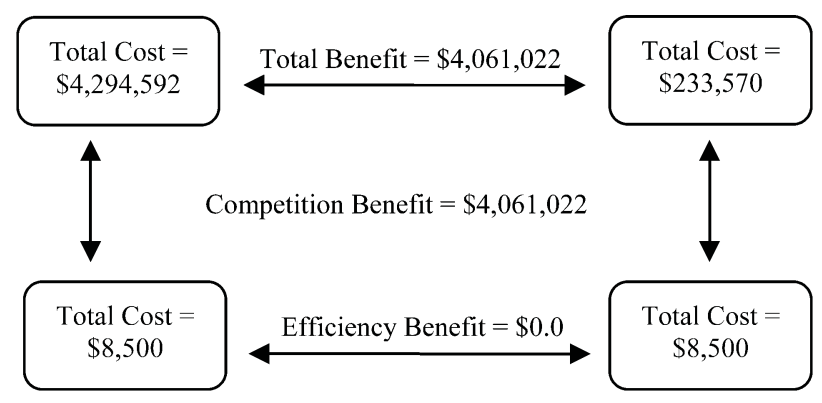

Fig. 8. Decomposition of total benefit of the transmission capacity added to the system to the competition benefit and efficiency benefit.

TABLE V

GENERATORS' DATA

\begin{tabular}{c|c|c}
\hline Generator & $\mathrm{g}^{\max }(\mathrm{MW})$ & $\mathrm{c}(\$ / \mathrm{MW})$ \\
\hline GenCo1 & 220 & 12 \\
\hline GenCo2 & 460 & 20 \\
\hline GenCo3 & 600 & 35 \\
\hline Total & 1280 & \\
\hline
\end{tabular}

TABLE VI

RETAILERS' DATA

\begin{tabular}{c|c|c}
\hline Retailer & $\mathrm{d}^{\max }(\mathrm{MW})$ & VoLL $(\$ / \mathrm{MW})$ \\
\hline $\mathrm{R} 1$ & 80 & 20,000 \\
\hline $\mathrm{R} 2$ & 130 & 40,000 \\
\hline R3 & 40 & 10,000 \\
\hline R4 & 160 & 30,000 \\
\hline R5 & 115 & 50,000 \\
\hline Total & 525 & \\
\hline
\end{tabular}

TABLE VII

TRANSMISSION NETWORK DATA

\begin{tabular}{c|c|c|c|c}
\hline Line\# & From & To & Reactance (Ohm.) & Limit(MW) \\
\hline 1 & Bus1 & Bus2 & 0.004 & 40 \\
\hline 2 & Bus1 & Bus4 & 0.006 & 50 \\
\hline 3 & Bus1 & Bus5 & 0.002 & 60 \\
\hline 4 & Bus2 & Bus3 & 0.002 & 180 \\
\hline 5 & Bus2 & Bus4 & 0.004 & 50 \\
\hline 6 & Bus2 & Bus6 & 0.003 & 40 \\
\hline 7 & Bus3 & Bus5 & 0.002 & 160 \\
\hline 8 & Bus4 & Bus6 & 0.003 & 100 \\
\hline
\end{tabular}

TABLE VIII

TRANSMISSION NETWORK AUgmeNTATION DATA

\begin{tabular}{c|c|c|c|c|c|c}
\hline Line\# & From & To & $\begin{array}{c}\text { Max. } \\
\text { number } \\
\text { of } \\
\text { Circuits } \\
\text { (Cct) }\end{array}$ & $\begin{array}{c}\text { Reactance } \\
\text { (Ohm.) }\end{array}$ & $\begin{array}{c}\text { Capacity } \\
\text { (MW/Cct) }\end{array}$ & $\begin{array}{c}\text { Transmission } \\
\text { Investment } \\
\text { cost (\$/Cct) }\end{array}$ \\
\hline 1 & Bus1 & Bus2 & 2 & 0.004 & 120 & 850,000 \\
\hline 2 & Bus1 & Bus4 & 2 & 0.006 & 180 & 500,000 \\
\hline 3 & Bus2 & Bus3 & 2 & 0.002 & 150 & 700,000 \\
\hline 4 & Bus2 & Bus6 & 2 & 0.003 & 120 & 550,000 \\
\hline 5 & Bus3 & Bus4 & 2 & 0.002 & 150 & 600,000 \\
\hline 6 & Bus3 & Bus5 & 2 & 0.003 & 160 & 100,000 \\
\hline 7 & Bus4 & Bus6 & 2 & 0.0061 & 160 & 540,000 \\
\hline 8 & Bus5 & Bus6 & 2 & 0.0061 & 140 & 120,000 \\
\hline
\end{tabular}

The strategy plane of each GenCo consists of ten actions. In each action, the price bid is set at marginal cost and the quantity bid varies from $10 \%$ to total generation capacity in steps of $10 \%$.

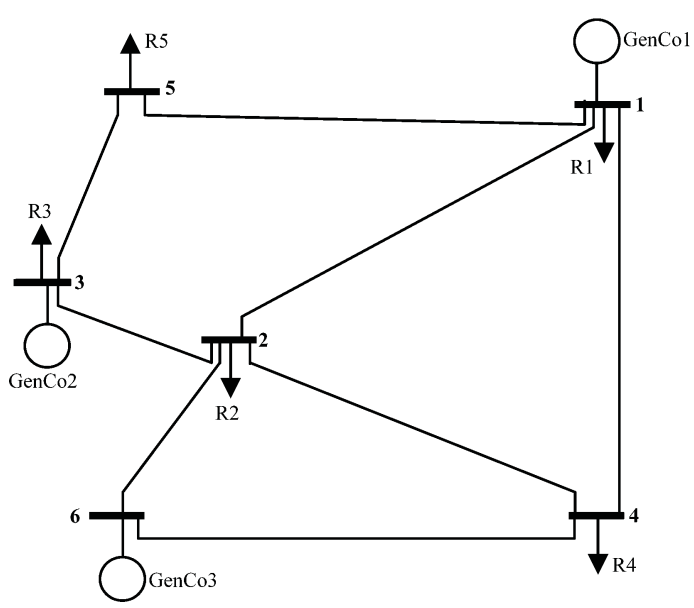

Fig. 9. Modified Garver's example system.

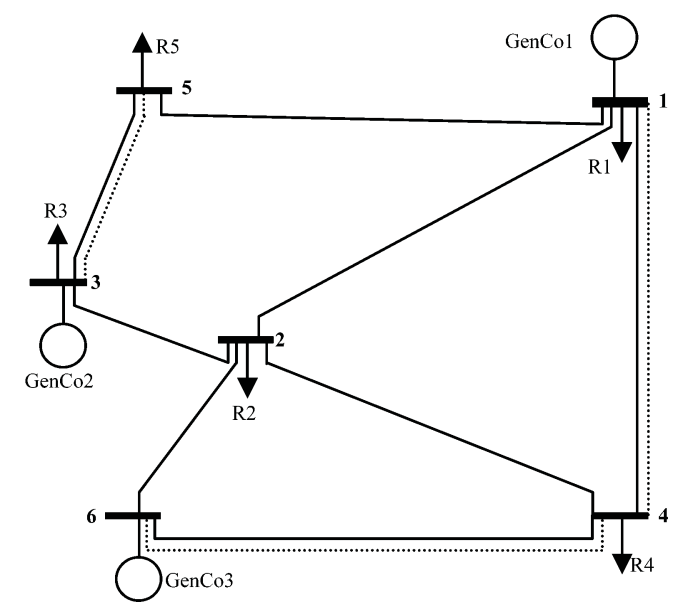

Fig. 10. Modified Garver's example system augmented by the traditional method (no augmentation) and proposed method (dashed lines).

As in the previous example, the traditional model of transmission planning approves no transmission augmentations in the proposed network (no augmentations pass the economic costbenefit test). In contrast, the proposed approach finds that the optimal planning schedule is the vector $\mathrm{n}=(0,1,0,0,0,1,1,0)$ (i.e., upgrades to lines 2, 6, and 7). This transmission planning schedule is shown in Fig. 10.

The price-quantity offers of the GenCos in the case of (A) the original transmission network (B) the transmission network augmented using the proposed methodology are reported in Table IX.

As in Table IX, the total offered capacity, the total withheld capacity, and $\mathrm{HHI}^{1}$ have been improved by $11.57 \%, 6 \%$, and $4.50 \%$, respectively. As shown in Table IX, the proposed approach results in a significantly lower total social cost than the traditional approach.

Fig. 11 decomposes the total benefit of the proposed augmentations into the competition benefit and the efficiency benefit.

As in Fig. 11, the efficiency benefit of the proposed transmission planning schedule is $1206(\$ / \mathrm{h})$, compared with an investment cost of $\$ 1140000$, so this planning schedule does not pass

${ }^{1}$ The Hirschmann-Herfindahl Index (HHI) of a market is the sum of the squares of the market shares of the firms which are active in the market. If the market share of firm $i$ is $s_{i}$, the HHI is then defined as HHI $=10000 \times \Sigma s_{i}^{2}$. 
TABLE IX

PRICE-QUANTITY OUTCOMES OF GENCOS 1, 2, AND 3 FOUND BASED ON THE WORST NASH EQUILIBRIUM

\begin{tabular}{|c|c|c|}
\hline & $\begin{array}{l}\text { Original Network - } \\
\text { Augmented Network, } \\
\text { traditional approach }\end{array}$ & $\begin{array}{l}\text { Augmented Network, } \\
\text { proposed approach }\end{array}$ \\
\hline $\begin{array}{c}\text { GenCo } 1 \\
\text { (\$/MW,MW) }\end{array}$ & $(12,220)$ & $(12,132)$ \\
\hline $\begin{array}{c}\text { GenCo } 2 \\
(\$ / M W, M W)\end{array}$ & $(20,92)$ & $(20,230)$ \\
\hline $\begin{array}{c}\text { GenCo } 3 \\
\text { (\$/MW,MW) }\end{array}$ & $(35,120)$ & $(35,120)$ \\
\hline $\begin{array}{c}\text { Total offered } \\
\text { capacity(MW) }\end{array}$ & 432 & $\begin{array}{c}482 \\
(11.57 \% \text { INC) }\end{array}$ \\
\hline $\begin{array}{l}\text { Total withheld } \\
\text { capacity(MW) }\end{array}$ & 848 & $\begin{array}{c}798 \\
(6 \% \mathrm{DEC}) \\
\end{array}$ \\
\hline $\mathrm{HHI}(\%)$ & 3818.59 & $3646.80(4.50 \%$ DEC $)$ \\
\hline $\begin{array}{c}\text { Total } \\
\text { Generation Cost } \\
(\$ / \mathrm{h}) \\
\end{array}$ & 8,680 & 10,384 \\
\hline $\begin{array}{l}\text { Total Value of } \\
\text { Lost Load }(\$ / \mathrm{h})\end{array}$ & $2,543,333$ & 460,000 \\
\hline $\begin{array}{l}\text { Total Social } \\
\text { Cost }(\$ / \mathrm{h})\end{array}$ & $2,552,013$ & 470,384 \\
\hline $\begin{array}{c}\text { TNSP } \\
\text { Cost }(\$) \\
\sigma=10.0\end{array}$ & $25,520,130$ & $5,843,840 \underline{(77.1 \% \mathrm{DEC})}$ \\
\hline
\end{tabular}

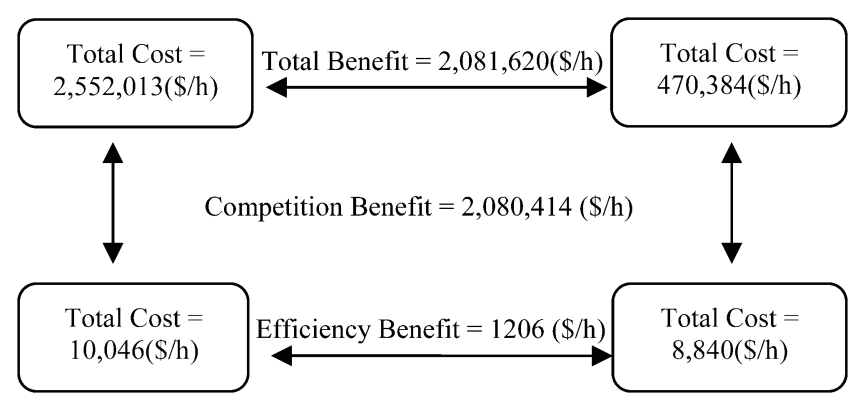

Fig. 11. Decomposition of total benefit of the transmission capacity added to the system to the competition benefit and efficiency benefit-proposed approach.

a cost-benefit test under the traditional approach. However, this transmission planning schedule has a competition benefit with total value of $2080414(\$ / \mathrm{h})$. Since the proposed mathematical structure captures both the efficiency benefit and the competition benefit of transmission capacity, the transmission planning schedule is approved under our proposed structure.

Fig. 12 shows that the prices at each of the buses after the transmission augmentation selected by the proposed approach are closer to the competitive locational prices than the prices that arise in the transmission system augmented by the traditional approach.

In both cases, case $\mathrm{A}$ and $\mathrm{B}$, the GenCos withdraw their capacity from the market in such a way that the available capacity is lower than the total demand, so that some load is shed. In this example, this load-shedding cannot be alleviated by transmission augmentation alone.

\section{CONCLUding REMARKS}

This paper derives and evaluates a mathematical structure which identifies economically-efficient transmission augmentations. The proposed mathematical structure is based on game

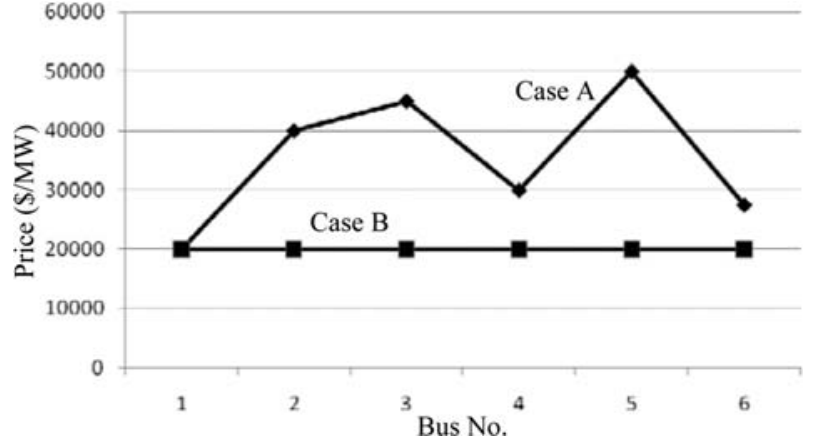

Fig. 12. Price at different buses in three cases of (A) original transmission network (B) augmented transmission network using the proposed approach.

theory concepts in applied mathematics. The TNSP, GenCos, and MMC are mathematically modeled in the proposed structure in a way which reflects the scope for strategic interaction in a liberalized electricity market. The structure has been designed in such a way as to allow an assessment of both the improvements in efficiency and the competitiveness resulting from a transmission augmentation. Policy makers can and should use transmission expansion decisions to increase competition between generators. The proposed mathematical structure and the associated numerical solution techniques (set out in another paper) are a promising framework towards achieving this goal.

\section{REFERENCES}

[1] P. L. Joskow, Pattern of Transmission Investment. Cambridge, MA: MIT Press, 2005.

[2] P. L. Joskow, "Patterns of transmission investment," in Proc. Electricity Infrastructure Investment Workshop, Paris, France, 2005.

[3] T. O. Leautier, "Regulation of an electric power transmission company," Energy J., vol. 21, no. 4, pp. 61-92, 2000.

[4] T. O. Leautier, "Transmission constraints and imperfect markets for power," J. Reg. Econ., vol. 19, no. 1, pp. 27-54, 2001.

[5] G. B. Shrestha and P. A. J. Fonseka, "Congestion driven transmission expansion in competitive power markets," IEEE Trans. Power Syst., vol. 19, no. 3, pp. 1658-1665, Aug. 2004.

[6] M. O. Buygi, H. M. Shanechi, G. Balzer, M. Shahidehpour, and N. Pariz, "Network planning in unbundled power systems," IEEE Trans. Power Syst., vol. 21, no. 3, pp. 1379-1387, Aug. 2006.

[7] M. O. Buygi, H. M. Shanechi, G. Balzer, M. Shahidehpour, and N. Pariz, "Market-based transmission expansion planning," IEEE Trans. Power Syst., vol. 19, no. 4, pp. 2060-2067, Nov. 2004.

[8] W. Lu, E. Bompard, R. Napoli, and X. Jiang, "Heuristic procedures for transmission planning in competitive electricity markets," Elect. Power Syst. Res. vol. 77, no. 10, pp. 1337-1348, 2006.

[9] P. Joskow and R. Schmalensee, Market for Power: An Analysis of Electric Utility Deregulation. Cambridge, MA: MIT Press, 1983.

[10] C. Wolfram, "Strategic bidding in a multi-unit auction: An empirical analysis of bids to supply electricity in England and Wales," RAND J. Econ., vol. 29, pp. 703-725, 1998.

[11] J. Bushnell, "Transmission rights and market power," Electr. J., pp. 77-85, 1999.

[12] P. Joskow and J. Tirole, "Transmission rights and market power on electric power network," RAND J. Econ., vol. 31, no. 3, pp. 450-487, Autumn, 2000.

[13] S. Borenstein, J. Bushnell, and S. Stoft, "The competitive effects of transmission capacity in a deregulated electricity industry," Univ. California Energy Inst., 1998, Power Working paper PWP-040R.

[14] T. O. Nasser, Imperfect Markets for Power: Competition and Residual Regulation in the Electricity Industry. Cambridge, MA: MIT Press, 1997.

[15] S. Sozer, C. S. Park, and J. Valenzuela, "Economic analysis of electric power transmission expansion," Eng. Economist, vol. 53, pp. 293-317, 2008.

[16] G. Latorre, R. D. Cruz, J. M. Areiza, and A. Villegas, "Classification of publications and models on transmission expansion planning," IEEE Trans. Power Syst., vol. 18, no. 2, pp. 938-946, May 2003. 
[17] J. Rosellon, "Different approaches towards electricity transmission expansion," Rev. Netw. Econ., vol. 2, no. 3, pp. 238-269, Sep. 2003.

[18] California ISO, Transmission Economic Assessment Methodology, 2004.

[19] Farrier Swier Consulting, An Analysis of Competition Benefits, Jul. 2003.

[20] Frontier Economics, Evaluating Interconnection Competition Benefits, Sep. 2004.

[21] B. Liu, "Stackelberg-Nash equilibrium for multilevel programming with multiple followers using genetic algorithm," Comput. Math. Appl., vol. 36, no. 7, pp. 79-89, 1998.

[22] M. Bazaar and C. M. Shetty, Nonlinear Programming, Theory and Applications. New York: Wiley, 1979.

[23] T. Weise, Global Optimization Algorithms-Theory and Application. [Online]. Available: http://www.it-weise.de.

[24] GAMS User Guide. [Online]. Available: http://www.gams.com/docs/ document.htm.

[25] J. P. Li, M. E. Balazs, G. T. Parks, and P. J. Clarkson, "A species conserving genetic algorithm for multimodal function optimization," Evol. Comput., vol. 10, no. 3, pp. 207-234.

[26] D. Beasley, D. R. Bull, and R. R. Martin, "A sequential niche technique for multimodal function optimization," Evol. Comput., vol. 1, no. 2, pp. 101-125, 1993.

[27] F. Glover, "Tabu search—Part I," J. Comput., vol. 1, no. 3, pp. 190-206, Summer, 1989.

[28] R. I. Lung and D. Dumitrescu, "Roaming optimization: A new evolutionary technique for multimodal optimization," Studia University, Babes-Bolyai, Informatica, vol. XLIX, no. 1, pp. 99-109, 2004.

[29] W. N. Martin, J. Lienig, and J. P. Cohoon, Island (Migration) Models: Evolutionary Algorithms Based on Punctuated Equilibria, Handbook of Evolutionary Computation.

[30] D. E. Goldberg and J. Richardson, "Genetic algorithms with sharing for multimodal function optimization," in Proc. 2nd Int. Conf. Genetic Algorithms, pp. 41-49, Lawrence Erlbaum Assoc.

[31] C. Y. Lin and Y. J. Yang, "Cluster identification techniques in genetic algorithms for multimodal optimization," in Computer-Aided Civil and Infrastructure Engineering. Oxford, U.K.: Blackwell, 1998, vol. 13, pp. 53-62.

[32] R. I. Lung and D. Dumitrescu, "A new evolutionary optimization technique," in Proc. Int. Conf. Theory and Applications of the Mathematics and Informatics-ICTAMI, Alba Iulia, Romania, 2003.

[33] R. I. Lung and D. Dumitrescu, "A new evolutionary model for detecting multiple optima," in Proc. GECCO, London, U.K., Jul. 7-11, 2007.

[34] R. Chandra, Parallel Programming in OpenMP. San Mateo, CA Morgan Kaufmann, 2001.

[35] E. Hansen and G. W. Walster, Global Optimization Using Interval Analysis: Revised and Expanded (Pure and Applied Mathematics). New York: Marcel Dekker, 2007.

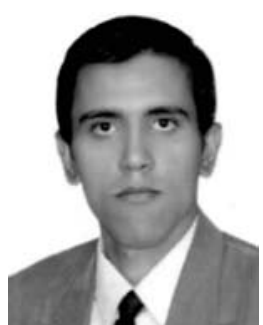

Mohammad R. Hesamzadeh (GS'08) received the B.Sc.E.E. and M.Sc.E.E. degrees. He is pursuing the Ph.D. degree at Swinburne University of Technology, Melbourne, Australia.

His special fields of interest include power system economics, high voltage transmission system planning and design, electricity market analysis, intelligent system applications in power systems, electrical distribution and rural system studies, and high voltage engineering.

Mr. Hesamzadeh was the Vice-Chair of IEEE Queensland, Power and Energy Chapter, in 2008. He is a Member of the Computer and Analytical Methods Subcommittee (CAMS) of the Power System Analysis, Computing, and Economics (PSACE) Committee of the IEEE. He is a Professional Engineer in Australia.

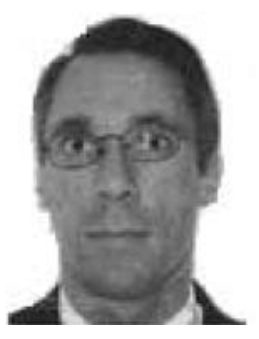

Darryl R. Biggar received the M.A. degree in mathematics from Cambridge University, Cambridge, U.K., and the Ph.D. degree in economics from Stanford University, Stanford, CA.

$\mathrm{He}$ is an economist with the Australian Competition and Consumer Commission and the Australian Energy Regulator. He specializes in the economics of regulation. He has a particular interest in electricity markets including issues of nodal and zonal pricing and the measurement and control of market power. $\mathrm{He}$ is a native of New Zealand.

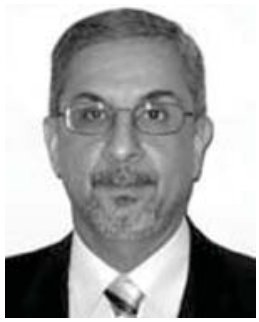

Nasser Hosseinzadeh (M'86) is currently with Swinburne University of Technology, Melbourne, Australia. Earlier, he worked as a Senior Lecturer at Central Queensland University in Australia, as a Lecturer at Monash University Malaysia, and as an Assistant Professor at Shiraz University, Shiraz, Iran. His special fields of interest include power system analysis and planning, wind energy systems, power system stability, applications of intelligent control in power engineering, and engineering education.

Dr. Hosseinzadeh is on the Australian Panel C1 (System Development and Economics) of CIGRE.

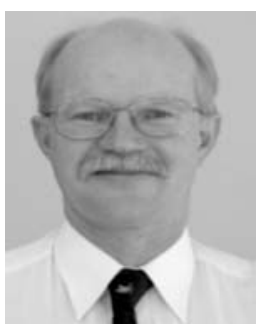

Peter J. Wolfs (M'80-SM'99) was born in Rockhampton, Australia, in 1959. He received the Ph.D. degree from the University of Queensland, Brisbane, Australia, in 1992.

$\mathrm{He}$ is the Western Power Chair of Power Engineering at the Department of Electrical and Computer Engineering at Curtin University, Bentley, Australia. His special fields of interest include smart grids, distributed generation, power quality and harmonics, rural power supply, photovoltaic systems, power electronics, and railway traction power supply.

Prof. Wolfs is a Fellow of Engineers Australia, a Registered Professional Engineer in the State of Queensland, and a member of the Railway Technical Society of Australia. 